\title{
Suppressive compost: when plant pathology met microbial ecology
}

\author{
Yitzhak Hadar
}

Received: 9 March 2011 / Accepted: 23 May 2011 /Published online: 11 June 2011

(C) Springer Science+Business Media B.V. 2011

Biography

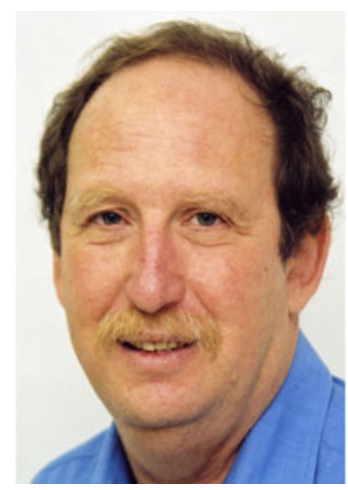

Yitzhak Hadar is a Professor of Microbiology at the Robert H. Smith Faculty of Agriculture, Food and Environment (FacAgric), The Hebrew Univ. of Jerusalem (HUJ), in Rehovot, Israel. He was born in Haifa, Israel, in 1951, and obtained his B.Sc. (1975) and M.Sc. (1977) degrees in Plant Protection, and Ph.D. (1980) from the HUJ. His doctoral work consisted of research on sclerotia formation in Sclerotium rolfsi. This was followed by a post doc at Cornell University's New York State Agricultural

Y. Hadar $(\bowtie)$

Department of Plant Pathology and Microbiology,

The Robert H. Smith Faculty of Agriculture,

Food and Environment,

The Hebrew University of Jerusalem,

Rehovot 76100, Israel

e-mail: hadar@agri.huji.ac.il
Experiment Station in Geneva, working with Professor Gary Harman on biological control. In 1981 Hadar accepted a lecturer position at the HUJ FacAgric, and was appointed Professor in 1995, teaching courses in general microbiology, environmental microbiology, and treatment and recycling of agricultural wastes. He was a Visiting Scientist at Repligen-Sandoz Research Corporation, Lexington, MA, USA (1988-89) and Honorary Lecturer at the Dept. of Biological Sciences, The University of Waikato, Hamilton, New Zealand (1996-97). He served as Dean of the FacAgric (2001-2005), Head of the Dept. of Microbiology and Plant Pathology (2006-2010), President of the Israeli Society for Microbiology (2006-2008) and is currently a member of the Executive Committee and Board of Managers, HUJ; on the Board of the Environment and Health Fund; and Head, The Joseph Saltiel Center for Pre-Academic Studies at the HUJ.

Professor Hadar's research interest is in environmental microbiology. Currently his research group has been studying mechanisms of degradation of recalcitrant aromatic compounds by white rot fungi with emphasis on the edible mushroom Pleurotus ostreatus, composting of agricultural wastes, suppression of soilborne pathogens, and microbial interactions in the rhizosphere.

Yitzhak Hadar is the author or co-author of 180 refereed journal publications and 35 book chapters and reviews and the co-editor of two books. 
Biological control of soilborne plant pathogens with suppressive composts is now an established horticultural approach. The concept of using composted hardwood bark as a peat substitute to control soilborne plant pathogens was suggested by Hoitink (1980). This compost was shown to suppress several pathogens which cause damage to plants grown in container media. Since the 1980 s a large number of experiments describing a wide array of pathosystems and composts from a broad variety of raw materials were described-suggesting that suppression of soilborne plant pathogens is a global phenomenon related to the nature of the composting process rather than to a single specific example. Bonanomi et al. (2007) reviewed reports on the application of organic amendments, focusing on the suppressive capacity of different organic materials and the response of different soilborne pathogens. A total of 250 articles were analyzed, with 2423 experimental case studies. Organic matter, as crop residues or compost amendments, was found to be suppressive in $45 \%$ and nonsignificant in $35 \%$ of the cases. In $20 \%$ of the cases, a significant increase of disease incidence was observed. Compost was the most suppressive material, with more than $50 \%$ of cases showing effective disease control. In their review, Noble and Coventry (2005 ) analyzed experiments conducted when compost was applied in container media, in the field or as turf grass top-dressing. They found that the effects in the field were generally smaller and more variable than those in container experiments. An interesting demonstration of the variability of the suppressive effect is the comprehensive study by Termorshuizen et al. (2006), who compared the effectiveness of 18 different composts on seven pathosystems. Significant disease suppression was found in $54 \%$ of the cases whereas only $3 \%$ of the cases showed significant disease enhancement. The authors highlight the point that no single compost showed significant disease suppression against all pathogens, as well as that the pathogens were not affected similarly by all composts. More than three decades of research on the suppressive effects of compost worldwide, demonstrate great potential. However, at the same time, the findings present a large variability and inconsistency in the success of such practice, and thus there are several difficulties to overcome. Therefore, investigations on the mechanisms by which compost populations act on plant diseases, in addition to the knowledge accumulated so far, are essential in order to make the use of these materials more predictable and provide means for quality control of commercial products.

Microbial activity in composts plays a major role in the suppression of soilborne plant pathogens (Hoitink and Fahy 1986). The disease-suppressive effect is usually lost following sterilization or pasteurization. Better understanding of the microbial behavior and structure of the antagonistic populations in the compost will provide tools to reduce its variability.

The following biological mechanisms of disease control were suggested for disease suppression by composts: direct parasitism of pathogens; antibiosis; competition for nutrients such as carbon or iron; compost population activating induced systemic resistance in the plants; and, improved plant nutrition and vigor, leading to enhanced disease resistance (Hoitink and Boehm 1999; Hoitink et al. 1993). These mechanisms may exist separately or in combinations. The first three affect the pathogen directly and reduce its survival while the latter two act indirectly via the plant and affect the disease cycle.

Competition for carbon source was discovered as the mechanism of suppression of the oomycete Pythium aphanidermatum. Oospores survived in disease-suppressive compost for over 6 months but could not germinate due to competition by the microbial population; consequently, disease did not develop (Hadar and Mandelbaum 1986; Mandelbaum and Hadar 1990). Yogev et al. (2006) characterized the ability of three plant residue-based composts to be suppressive towards formae speciales of Fusarium oxysporum: melonis, basilici, radicis-lycopersici and radicis-cucumerinum. Disease development in melon, tomato and cucumber seedlings growing in the three composts was significantly less than that observed in peat. The tested formae speciales exhibited different decline rates of the viable conidia incorporated into the composts, compared with the rate in the peat control, which suggests that different mechanisms may be involved in the suppression of the different pathogens. Yogev et al. (2010) demonstrated that induced resistance could be an additional mechanism involved in Fusarium disease suppression by composted manure and tomato residues. Little has been reported on suppression of bacterial diseases. The ability of compost to suppress Clavibacter michiganense subsp. michiganensis was reported for tomatoes 
grown under commercial greenhouse conditions, where natural infection occurred (Yogev et al. 2009). In another study (Danon et al. 2007), mature biosolids compost was found to be suppressive towards germination of sclerotia of Sclerotium rolfsii. However, during prolonged curing suppression of sclerotia germination was reduced by more than $50 \%$, and also in plant assays where suppression of disease development was reduced by more than $60 \%$. Correlations were found between the decrease and subsequent loss of suppression of sclerotia germination and the decrease in $\mathrm{pH}$, dissolved organic carbon and $\mathrm{NH}_{4}{ }^{+}$concentrations and an increase in $\mathrm{NO}_{3}{ }^{-}$ concentration. It was concluded that parasitism of sclerotia by antagonistic fungi occurred only when they were weakened in the presence of $\mathrm{NH}_{3}$ at the higher $\mathrm{pH}$ level. This study presents a case where direct parasitism is the mechanism of suppression but occurs only under the proper chemical conditions (Zmora-Nahum et al. 2008). It is also important to pay more attention to events occurring in the rhizosphere as well as seed surfaces of plants grown in the presence of compost, since this is the location of communication among the compost community, the pathogen and the plant (Minz et al. 2010).

In the case of biological control using suppressive compost, the activity is attributed to a diverse microbial community rather than to a population of a single defined species augmented to infested soil. Thus it is imperative to have the capacity to study the composition, structure and function of a microbial community in its natural environment. It is apparent therefore that understanding compost microbiology is the key for understanding mechanisms of suppression and population dynamics. Most of the past research on compost microbiology was performed using culturing techniques; however, it is estimated for soils that less than $1 \%$ of the viable microbiota is cultivable with current techniques (Torsvik et al. 1990). For composts the percentage is unknown, and molecular techniques suggest that, also in composts, numerous microorganisms prevail that currently cannot be isolated (Ivors et al. 2000). The study of microbial interactions in a natural environment such as soil or compost must also be dependent on noncultivating methods based on molecular characteristics. Molecular tools offer an alternative to, and complement cultivation-based techniques of monitoring microbial populations. These molecular techniques usually target information-bearing macromolecules such as RNA,
DNA, or lipids (Minz et al. 2010). Danon et al. (2008) analyzed the biosolids compost communities at different stages of prolonged curing exhibiting different levels of suppression using three PCR-based molecular methods (DGGE, clone library and microarray). All three methods indicated distinctive community shifts during curing and the dominant species prevailing during the different curing stages were identified. Proteobacteria were the most abundant phylum in all cases, whereas Bacteroidetes and Gammaproteobacteria were ubiquitous. During the mid-curing stage, Actinobacteria were dominant. Different members of nitrifying bacteria and cellulose- and macromoleculedegrading bacteria were found throughout the curing process. In contrast, bacterial pathogens were not detected even after a year of curing.

In recent years mass sequencing technologies, also known as "Next generation sequencing," have been developed and have the ability to process millions of sequence reads in parallel. It requires the large-scale operation of a specialized and devoted infrastructure of robotics, bioinformatics, computer databases and instrumentation. Concomitantly with the dramatic technological advances and the size of data bases available, the cost of analyses is reduced constantly (Kakirde et al. 2010). Metagenomics and metatranscriptomics along with the appropriate bioinformatics may facilitate not only the analyses of phylogenetic relationships but also to tie community composition and structure to functions. Identifying specific genes from ecosystems such as compost, which have a high degree of microbial diversity, is challenging. Recent metagenome studies have demonstrated that it is possible to assign functional annotations to partial gene sequences from shotgun sequence reads with a reasonable degree of accuracy. It is anticipated that with the development of such techniques and their application to suppressive compost studies, more of its secrets will be revealed.

A difficulty of practical importance on the road to routine and reliable application of compost to suppress soilborne plant diseases is to develop methodology by which disease suppression can be predicted for an individual pile of compost or, in other words, to develop criteria for the quality control of suppressive compost. The capability to predict disease suppression on the basis of pure compost characteristics will be highly advantageous, since compost producers will be able to optimize the composting process based on disease suppression goals, in addition to the compost benefits in improving 
soil properties and fertility, thus enabling growers to choose the appropriate compost for the specific disease jeopardizing the crop they wish to cultivate.

Suppressive compost is an outstanding example of environmentally friendly agricultural practice, since it has many benefits and provides environmental service to the society. The raw material for composting is always a waste material of agricultural or municipal source; the compost replaces fertilizers and improves soil structure in the case of field applications or replaces peat, a nonrenewable resource, in the case of container media in horticulture; and, suppression of soilborne diseases reduces the need for pesticides or disinfection. This approach is acceptable for organic agriculture but can be easily adopted by conventional farming and integrated into the farmer's routine practice. An important step towards application of suppressive compost could be the development of quality control tools that may reduce the variability in efficacy. Unfortunately, a single chemical or physical, easy-to-perform parameter could not predict suppression, and thus quality control is dependent on bioassays designed for a specific pathogen or disease. Despite the increasing amount of information regarding suppressive compost, some challenges remain: the proven success of applications into container media should be translated to field soils; comprehensive appreciation of the microbial community structure, composition and function leading to a suppressive compost but also understanding of events in the rhizosphere - the site of interaction among the compost, the pathogen and the plant. Profound understanding of microbial ecology processes could also provide directions for possible manipulations of the community leading to a reproducible suppressive compost.

Acknowledgment I wish to thank Harry Hoitink for introducing me to this fascinating field.

\section{References}

Bonanomi, G., Antignani, V., Pane, C., \& Scala, F. (2007). Suppression of soilborne fungal diseases with organic amendments. Journal of Plant Pathology, 89, 311-324.

Danon, M., Frank-Whittle, I. H., Insam, H., Chen, Y., \& Hadar, Y. (2008). Molecular analysis of bacterial community succession during prolonged compost curing. FEMS Microbiology Ecology, 65, 133-144.

Danon, M., Zmora-Nahum, S., Chen, Y., \& Hadar, Y. (2007). Prolonged compost curing reduces suppression of Sclerotium rolfsii. Soil Biology and Biochemistry, 39, 1936-1946.
Hadar, Y., \& Mandelbaum, R. (1986). Suppression of $P$. aphanidermatum damping-off in container media containing composted licorice roots. Crop Protection, 5, 88-92.

Hoitink, H. A. J. (1980). Composted bark, a light weight growth medium with fungicidal properties. Plant Disease, 64, 142-147.

Hoitink, H. A. J., \& Boehm, M. J. (1999). Biocontrol within the context of soil microbial communities: A substrate-dependent phenomenon. Annual Review of Phytopathology, 37, 427-446.

Hoitink, H. A. J., Boehm, M. J., \& Hadar, Y. (1993). Mechanism of suppression of soil borne plant pathogen in compost-amended substrates. In H. A. J. Hoitink \& H. M. Keener (Eds.), Science and engineering of composting: Design, environmental, microbiological and utilization aspects (pp. 601-621). Worthington, OH, USA: Renaissance Publications.

Hoitink, H. A. J., \& Fahy, P. C. (1986). Basis for the control of soilborne plant pathogens with composts. Annual Review of Phytopathology, 24, 93-114.

Ivors, K. L., Collopy, P. D., Beyer, D. M., \& Kang, S. (2000). Identification of bacteria in mushroom compost using ribosomal RNA sequence. Compost Science and Utilization, 8, 247-253.

Kakirde, K. S., Parsley, L. C., \& Liles, M. R. (2010). Size does matter: Application-driven approaches for soil metagenomics. Soil Biology and Biochemistry, 42, 1911-1923.

Mandelbaum, R., \& Hadar, Y. (1990). Effects of available carbon source on microbial activity and suppression of Pythium aphanidermatum in compost and peat container media. Phytopathology, 80, 794-804.

Minz, D., Green, S. J., \& Ofek, M. (2010). Compost microbial populations and interactions with plants. In H. Insam, M. Goberna, \& I. Franke-Whittle (Eds.), Microbes at workfrom wastes to resources (pp. 231-251). Dordrecht, the Netherlands: Springer-Verlag.

Noble, R., \& Coventry, E. (2005). Suppression of soil-borne plant diseases with composts: a review. Biocontrol Science and Technology, 15, 3-20.

Termorshuizen, A. J., van Rijn, E., van der Gaag, D. J., Alabouvette, C., Chen, Y., Lagerlőf, J., et al. (2006). Suppressiveness of 18 composts against 7 pathosystems: Variability in pathogen response. Soil Biology and Biochemistry, 38, 2461-2477.

Torsvik, V. L., Goksoyr, J., \& Daae, F. L. (1990). High diversity in DNA of soil bacteria. Applied Environmental Microbiology, 56, 782-787.

Yogev, A., Raviv, M., Hadar, Y., Cohen, R., \& Katan, J. (2006). Characterization of composts suppressive towards Fusarium pathogens and diseases. European Journal of Plant Pathology, 116, 267-278.

Yogev, A., Raviv, M., Hadar, Y., Cohen, R., Wolf, S., Gil, L., et al. (2010). Induced resistance as a putative component of compost suppressiveness. Biological Control, 54, 46-51.

Yogev, A., Raviv, M., Kritzman, G., Hadar, Y., Cohen, R., Kirshner, B., et al. (2009). Suppression of bacterial canker of tomato by composts. Crop Protection, 28, 97-103.

Zmora-Nahum, S., Danon, M., Hadar, Y., \& Chen, Y. (2008). Chemical properties of compost extracts inhibitory to germination of Sclerotium rolfsii. Soil Biology and Biochemistry, 40, 2523-2529. 